\title{
PENERIMAAN SISTEM PEMBELAJARAN BAHASA ARAB DENGAN E- LEARNING DAN GIM DI MASA PANDEMI COVID-19
}

\section{ARABIC LANGUAGE LEARNING SYSTEM ACCEPTANCE WITH E-LEARNING AND GAMES IN THE COVID-19 PANDEMIC}

\author{
Dewi Khairani ${ }^{1, *}$, M. Iqbal Prayoga ${ }^{2}$, Dede Rosyada ${ }^{2}$, Zulkifli $^{3}$, Fitri Mintarsih ${ }^{1}$ \\ ${ }^{1}$ UIN Syarif Hidayatullah Jakarta, Fakultas Sains dan Teknologi \\ ${ }^{2}$ UIN Syarif Hidayatullah Jakarta, Fakultas Tarbiyah \\ ${ }^{3}$ UIN Syarif Hidayatullah Jakarta, Fakultas Ilmu Sosial dan Ilmu Politik \\ email: dewi.khairani@uinjkt.ac.id
}

Naskah Diterima: 8 Desember 2020; Direvisi: 23 November 2021; Disetujui: 15 Desember 2021

\begin{abstract}
This study discusses the acceptance of the use of e-learning and games in learning Arabic during the COVID-19 pandemic. Arabic learning experienced considerable challenges in learning before the pandemic and now with the pandemic, this process has even greater challenges which ultimately require an Arabic language learning method that adapts to the generation, situation and condition of the people who are experiencing the COVID-19 pandemic so that learning can still be carried out with good and fun outcomes. This research through its five hypotheses which are built based on the Technology Acceptance Model (TAM) theory, shows that with the use of e-learning and games, a positive perception of convenience which then supports usefulness and ultimately affects the attitudes and behaviour of users in learning Arabic can be proven by the acceptance of the five the hypothesis. The consistent use of e-learning and games in learning, especially Arabic learning and the implementation of e-learning and games to support the curriculum are expected to improve student learning experiences for the better and also increase the actual use of both methods.
\end{abstract}

Keywords: Acceptance model; Arabic; Covid-19; E-Learning; Game; Learning; Online

\begin{abstract}
Abstrak
Penelitian ini membahas tentang penerimaan penggunaan e-learning dan gim dalam pembelajaran Bahasa Arab selama Pandemi COVID-19. Pembelajaran Bahasa Arab mengalami tantangan yang cukup besar dalam pembelajaran sebelum pandemi dan sekarang dengan adanya pandemi, proses ini memiliki tantangan yang lebih besar yang akhirnya membutuhkan sebuah metode pembelajaran bahasa Arab yang menyesuaikan dengan situasi generasi, situasi dan kondisi masyarakat yang sedang mengalami pandemi COVID-19 agar pembelajaran tetap dapat dilaksanakan dengan hasil keluaran yang baik dan menyenangkan. Penelitian ini melalui kelima hipotesisnya yang dibangun berdasarkan teori Technology Acceptance Model (TAM), menunjukkan bahwa dengan penggunaan e-learning dan gim, persepsi positif tentang kemudahan yang kemudian menunjang kebermanfaatan dan akhirnya mempengaruhi sikap dan perilaku pengguna dalam pembelajaran bahasa Arab dapat dibuktikan dengan penerimaan kelima hipotesis tersebut. Penggunaan e-learning dan gim secara konsisten dalam pembelajaran khususnya pembelajaran Bahasa Arab dan implementasi e-learning dan gim untuk mendukung kurikulum diharapkan dapat meningkatkan pengalaman belajar siswa menjadi lebih baik dan juga meningkatkan penggunaan keduanya secara aktual.
\end{abstract}

Kata kunci: Covid-19; Bahasa Arab; Daring; E-Learning; Gim; Model Penerimaan 


\section{PENDAHULUAN}

Metode pembelajaran dengan modifikasi sangat dibutuhkan bagi para guru ataupun pengajar lainya dalam mengatasi kesulitan dalam kegiatan belajar dan mengajar (KBM) di masa pandemi seperti yang saat ini sedang dihadapi. Siap tidak siap, baik guru maupun murid harus menghadapi kenyataan kondisi yang sangat berat sehingga berdampak pada bidang pendidikan dimana guru dan murid dituntut untuk bisa beradaptasi dengan pembelajaran secara daring dengan cepat, pembelajaran harus bergerak variatif dan menyenangkan agar terciptanya suasana pembelajaran yang menarik meskipun dalam keadaan daring.

Dalam hal keterlibatan diri sebagai pembelajar, Piaget (Henniger, 2014) menekankan bahwa anak-anak secara aktif membangun dunia kognitif mereka sendiri, informasi dari lingkungan tidak begitu saja dituangkan ke dalam pikiran-pikiran mereka. Maka dari itu konsep pembelajaran yang dirancang harus relevan terhadap keadaan. Tetapi, untuk menjadi orang tua didik yang ideal tentu tidaklah mudah dan secepat itu karena mereka masih banyak butuh bimbingan secara terpadu. Menurut Umar Tirtaharja tujuan pendidikan harus memuat gambaran tentang nilai-nilai yang baik, luhur pantas, benar dan indah, untuk kehidupan (Umar Tirtaharja, 1995). Karena itu tujuan pendidikan mempunyai dua fungsi yaitu memberikan arah kepada segenap kegiatan pendidikan dan merupakan sesuatu yang ingin dicapai oleh segenap kegiatan pendidikan. Pada dasarnya, pendidikan dalam perspektif Islam berupaya mengembangkan seluruh potensi peserta didik seoptimal mungkin, baik yang menyangkut aspek jasmaniah maupun rohaniah, akal dan akhlak. Dengan optimalisasi seluruh potensi yang dimilikinya, pendidikan Islam berupaya mengantarkan peserta didik kearah kedewasaan pribadi secara paripurna yaitu yang beriman dan berilmu pengetahuan.

Dalam hal sama juga berlaku untuk pengajaran dalam topik-topik dalam pembelajaran di lembaga pendidikan. Pengajar perlu membuat beberapa penyesuaian tentang bagaimana mata pelajaran harus diajarkan untuk membuatnya kompetitif dan mudah dipelajari. Multimedia adalah salah satu alat yang sesuai dengan minat siswa digital yang dapat membuat pelajaran menjadi menarik dan menyenangkan. Selain itu, multimedia adalah alat interaktif yang menggabungkan berbagai elemen, termasuk teks, grafik, audio, video dan animasi yang dapat membangkitkan minat siswa. Sebagian besar siswa tidak hanya pelajar auditori atau visual, tetapi juga pelajar multiindera. Multimedia memiliki kemampuan untuk menarik perhatian pelajar karena membahas berbagai gaya belajar. Pelajar saat ini juga berharap untuk menggunakan perangkat media digital dalam kehidupan sehari-hari mereka, sehingga perangkat ini, atau teknologi media serupa, harus diintegrasikan ke dalam pengalaman kelas mereka (Shelly, Gunter and Gunter, 2012).

Kemajuan terbaru dalam teknologi saat ini telah membawa dan mengedepankan pendekatan inovatif baru yang juga menantang pendekatan konvensional untuk pengajaran dan pembelajaran. Selama bertahun-tahun, kemunculan pembelajaran berbasis komputer dan internet telah menyediakan sumber daya dan peluang besar dalam penggunaan alat, pendekatan, dan strategi inovatif untuk pengajaran dan pembelajaran seperti dalam pengajaran bahasa, sains hingga kedokteran. Salah satu platform efektif yang dapat mengoptimalkan pembelajaran di kalangan pengguna perangkat digital adalah penggunaan gim digital. Penggunaannya saat ini telah banyak diakui sebagai alat belajar yang baik karena dapat memotivasi siswa untuk menjadi peserta aktif dalam proses belajar mengajar (Alessi and R.Trollip, 2001; Baid and Lambert, 2010; Kirikkaya, Işeri and Vurkaya, 2010; Hamizul and Rahimi, 2015).

Studi sebelumnya menunjukkan bahwa penggunaan gim digital dapat meningkatkan pengetahuan siswa, mengembangkan lingkungan kelas yang menyenangkan, meningkatkan kesenangan siswa melalui proses pembelajaran dan membantu mengembangkan keterampilan lunak seperti kepemimpinan dan pengambilan keputusan (Paiva et al., 2016)(Sung and Hwang, 2013)(Hwang, Wu and Chen, 2012)(Papastergiou, 2009).

Gim edukasi digital juga dapat menghadirkan integrasi elemen multimedia 
yang sukses untuk tujuan pembelajaran (Mayer, 2002). Selama bertahun-tahun, gim digital edukatif menjadi lebih kreatif, inovatif, dan dinamis. Penggunaan gim ini dalam proses belajar mengajar telah menarik minat yang cukup besar dari berbagai pemangku kepentingan dalam pendidikan. Para ahli telah menganjurkan bagaimana permainan secara umum dapat digunakan untuk meningkatkan hasil belajar bahasa kedua/asing seperti membantu siswa untuk lebih menghafal kosa kata dan makna dan memodelkan pengucapan kata-kata dalam bahasa asing (Kalyuga, Mantai and Marrone, 2013). Selain itu, penelitian telah menemukan potensi gim digital sebagai platform interaktif yang mendorong pembelajaran aktif dan memfasilitasi pengembangan keterampilan berpikir kritis di antara pelajar bahasa kedua atau asing. Akibatnya, praktisi dan peneliti semakin menggunakan pembelajaran berbasis gim digital sebagai bagian dari pendekatan dan strategi pengajaran bahasa mereka.

Menyikapi hal tersebut perlu adanya pemikiran untuk menggunakan media baru dalam pembelajaran. Berdasarkan hasil studi Minako Sakai, tentang kecenderungan orientasi keagamaan masyarakat Islam kontemporer di Indonesia. Menurut Sakai, munculnya media baru dalam Seeking religious knowledge seperti internet, film, video, media online, dan berbagai media cetak lainnya, cenderung semakin fungsional pada generasi baru muslim Indonesia. Bahkan Sakai memprediksi 50\% orang Islam akan mencari pengetahuan agama lewat media cetak dan internet pada tahun 2015 (Sakai, 2012). Berdasarkan penelitian Pusat Pengkajian Islam dan Masyarakat (PPIM) UIN Syarif Hidayatullah Jakarta tahun 2017 bahwa sumber paling dominan pengetahuan agama generasi milenial adalah internet, mulai dari blog, website, hingga media sosial presentasinya menyentuh angka 54,87 persen. Sedangkan sumber pengetahuan agama melalui pengajian hanya 14,31 persen. [1] Dari penelitian tersebut bisa dilihat adanya pergeseran budaya dalam mendapatkan informasi dan pengetahuan. Oleh sebab itu pengelola lembaga pendidikan harus bisa memadukan pembelajaran di kelas dengan teknologi sekaligus memberikan rambu- rambu yang positif dalam mengambil manfaat dari media baru tersebut.

Salah satu objek menarik untuk diamati dalam kaitannya dengan penelitian yang diajukan oleh penulis adalah pengajaran dan pembelajaran Bahasa Arab, yang juga merupakan penciri dari Perguruan Tinggi Keagamaan Islam Negeri. Pengajaran dan pembelajaran bahasa Arab telah berakar selama ratusan tahun di Indonesia dimana pengajaran bahasa Arab terus berkembang bahkan di abad ke-21. Arti budaya, ekonomi dan agama dari bahasa Arab telah mendorong banyak orang Indonesia, khususnya Muslim untuk belajar bahasa tersebut. Akibatnya, kelas bahasa Arab ditawarkan di berbagai tingkatan di negara ini. Di tingkat Madrasah Ibtidaiyah, bahasa Arab diajarkan berdasarkan pada Kurikulum Standar untuk murid madrasah yang berfokus pada penguasaan keterampilan berbahasa Arab. Selain itu, di tingkat tersier, ada penawaran luas program bahasa Arab atau mata pelajaran bahasa Arab oleh banyak lembaga publik dan swasta pendidikan tinggi, dengan beberapa lembaga seminar dan lokakarya organisasi untuk mengembangkan dan meningkatkan kemahiran bahasa Arab di antara siswa dan guru. Jumlah pelajar bahasa Arab di berbagai tingkatan telah meningkat dari waktu ke waktu (Dollah et al., 2017)

Bahasa Arab juga telah menjadi bahasa resmi Perserikatan Bangsa-Bangsa (PBB) di samping bahasa Inggris, Prancis, Spanyol, Rusia, dan Cina sejak Januari 1971. Bahasa Arab juga merupakan bahasa yang digunakan dalam Al-Qur'an, kitab suci umat Islam, dan seperti itu adalah agama dan bahasa yang menjadi pemersatu semua Muslim, terlepas dari mana asalnya (Kaye and Holes, 1997). Metode paling cepat untuk mempelajari bahasa ini adalah dengan mendengarkannya terlebih dahulu dan kemudian mengulangi apa yang telah didengar oleh pelajar. Alat bantu audiovisual adalah langkah penting berikutnya dalam mengajar, terutama dalam mengajar bahasa kepada penutur bahasa lain (Maskor et al., 2016).

Dalam hal pembelajaran bahasa Arab sebagai bahasa kedua atau asing, perolehan target keterampilan bahasa adalah salah satu kriteria paling penting yang berkontribusi pada 
pengukuran kemahiran bahasa bagi siswa (Maskor et al., 2016). Namun, terlepas dari berbagai usaha untuk mengajarkan bahasa Arab kepada siswa di sekolah, banyak siswa yang belajar Bahasa Arab masih menunjukkan kurangnya penguasaan keterampilan bahasa Arab dasar. Para siswa juga nampak enggan dan kurang percaya diri untuk menggunakan bahasa Arab di luar kelas (bin Samah et al., 2016).

Tahun 2020 merupakan tahun yang menantang dikarenakan pandemi yang berdampak pada seluruh sektor kehidupan manusia baik ekonomi, pariwisata, politik bahkan berdampak pada sektor pendidikan, dalam hal pendidikan, sekitar $85 \%$ aktifitas beralih pada metode pembelajaran daring/daring dikarenakan demi menjaga aset anak bangsa. Momen ini menjadikan evaluasi besar pagi pendidikan di Indonesia sebab fasilitas jaringan internet yang belum merata ke seluruh nusantara, pada tahun 2019 dari total populasi sebanyak 264 juta jiwa penduduk Indonesia, ada sebanyak 171,17 juta jiwa atau sekitar 64,8 persen yang sudah terhubung ke internet. Hal ini menunjukan bahwa Indonesia merupakan negara yang cepat dalam beradaptasi transformasi pengelolaan belajar.

Begitu pula dengan pembelajaran bahasa Arab kini beralih menggunakan media elektronik e-learning, guru bahasa Arab dituntut agar menguasai media elektronik guna mengatasi pembelajaran secara daring, berbagai cara yang digunakan para guru untuk memaksimalkan pembelajaran bahasa Arab meskipun secara daring maka dari itu untuk menciptakan pembelajaran yang menarik dan sesuai keadaan dibutuhkan kreasi seorang guru dalam mengelola metode, strategi dan konsep dalam mengatur kelas secara daring sehingga proses kegiatan belajar mengajar dapat dirasakan sangat baik oleh para muridmuridnya.

Dengan adanya problematika pembelajaran bahasa Arab secara daring baik masalah jaringan, metode yang jenuh, membosankan dan sama sekali tidak sesuai dengan pengembangan materi dan kurikulum, juga bahwa ada beberapa guru yang belum bisa mengelola kelas secara daring dengan maksimal dan tepat sasaran terhadap kebutuhan pelajar. Dengan adanya tantangan ini penulis menyajikan metode yang tetap dengan konsep elektronik learning dan gim dalam pembelajaran bahasa Arab disaat pandemi dengan harapan dapat menciptakan suasana belajar yang menarik, inovatif, kreatif, efektif dan menyenangkan.

Melalu penelitian-penelitian yang akan dijabarkan pada bab selanjutnya, mayoritas setuju bahwa dengan mengembangkan media, metode dan strategi baru, salah satunya penggunaan gim dalam belajar, khususnya pembelajaran Bahasa, dan menjalankan proses pembelajaran maka dapat meningkatkan pengalaman belajar siswa menjadi lebih baik. (Alomar, Wanick and Wills, 2016; Zeroual, El Kah and Lakhouaja, 2017; Jasni, Zailani and Zainal, 2018a; Alshammari, 2020; Putri Fajriati et al., 2020). Hal ini tentunya dapat merangsang mereka untuk lebih tertarik untuk belajar. Namun kebanyakan pembelajaran yang ada, masih bersifat tematik dan belum didasarkan pada kurikulum tertentu yang memang dirancang khusus untuk mendukung proses pembelajaran yang dipandu oleh instruktur dan dapat dijalankan sebagai alat bantu instruksional di kelas.

\section{KAJIAN TEORI}

\section{E-Learning}

Teknologi informasi atau Information Technology yang biasanya disingkat sebagai IT merupakan kombinasi fungsi dari hardware, software, useware. IT juga merupakan sistem dan metode sebagai sarana dan prasarana untuk memperoleh informasi, mengirim, mengolah dan menyimpan berbagai data informasi akurat.

Pada kajian (Jasni, Zailani and Zainal, 2018b) peneliti mencari tahu "Apakah pembelajaran bahasa Arab memerlukan suntikan dan inovasi baru? Apakah pendekatan gamifikasi menjadi trend pembelajaran di abad ke-21?" melalui metode kajian literatur. Konsep gamifikasi banyak dilaksanakan dalam pembelajaran bertujuan agar meningkatkan pengalaman pembelajaran hal ini menunjukkan gamifikasi dapat memupuk sikap positif menerusi aktiviti permainan yang bersifat pendidikan dan menunjukan bahwa pendekatan gamifikasi jelas menyumbang kepada faktor yang positif dalam proses pembelajaran dan 
sangat relevan untuk diaplikasikan dalam konteks pembelajaran bahasa Arab.

Konsep pembelajaran yang santai dapat mempengaruhi psikologi dan tingkah laku positif dalam kalangan pelajar. Permainan bahasa mampu mengurangkan kerisauan, menggalakkan pelajar yang pemalu untuk berkomunikasi dan meningkatkan kemahiran sosial dan kemahiran interpersonal mereka (Fairosnita Ibrahim and Kamarul Shukri Mat Teh, 2015). Penguasaan bahasa Arab bukanlah suatu hal yang mudah untuk dipahami secara cepat, diperlukan pengulangan latihan secara terus-menerus perlu dipupuk agar bahasa sasaran dapat dikuasai dengan sebaliknya.

Berdasarkan penelitian sebelumnya pengembangan sebuah aplikasi pembelajaran bahasa Arab oleh (Santoso and Fitriansyah, 2017). Mereka mengusulkan solusi sebuah metode baru pembelajaran bahasa Arab dengan mengimplementasi aplikasi pembelajaran mobile sehingga orang-orang dapat belajar dengan mudah, dimanapun dan kapanpun. Hasil evaluasi berupa rekomendasi diantaranya rekomendasi materi secara umum, kosakata dan grammar.

Kondisi pandemi saat ini sebenarnya menjadi salah satu tantangan yang memberikan peluang dan prospek yang dapat diusahakan untuk dihadapi dengan cara berpikir positif ( $\mathrm{al}$ tafkîr al-îjââi) dan bersikap penuh kesungguhan dan kearifan menurut (Wahab, 2007). Menurutnya pula, ada beberapa prospek studi bahasa Arab di masa depan yang dapat ditekuni apabila para penggiat dan peminat studi bahasa Arab secara bersama-sama mau dan mampu menekuninya dan mengubah tantangan menjadi peluang, salah satunya adalah dengan mengembangkan media dan teknologi pembelajaran bahasa Arab.

Proses mengimplementasikan sebuah media dan pemanfaatan teknologi informasi di lembaga pendidikan adalah sebuah fenomena yang kompleks, karena terdiri dari banyak faktor yang dapat berkontribusi pada keberhasilan atau kegagalan inisiatif dari integrase penggunaannya (Murray and Olcese, 2011)(Orr, 2010). Salah satu elemen penting dari proses ini adalah kerja sama para guru (Chen, Looi and Chen, 2009). Oleh karena itu, penting bagi para pemimpin Lembaga
Pendidikan untuk menyadari kesiapan dan penerimaan pengajar terhadap teknologi yang diberlakukan untuk digunakan dalam pengajaran, selain itu juga penting untuk memahami faktor-faktor yang berkontribusi terhadap sikap para pengajar ini, hal ini mampu menjadi alat yang sangat berguna untuk memprediksi apakah suatu media dan teknologi pembelajaran berhasil atau gagal dalam pengimplementasianya, dan juga untuk mendeteksi dan memperbaiki kemungkinan kesalahan yang dapat muncul akibat penerapan teknologi tersebut.

Sistem pembelajaran yang didasarkan pada pengajaran formal tetapi dengan bantuan sumber daya elektronik dikenal sebagai Elearning (Khairani et al., 2020). Meskipun pengajaran dapat dilakukan di dalam atau di luar kelas, penggunaan komputer dan Internet merupakan komponen utama dari E-learning. Elearning juga dapat disebut sebagai jaringan yang memungkinkan transfer keterampilan dan pengetahuan, dan penyampaian pendidikan dilakukan kepada sejumlah besar penerima pada waktu yang sama atau berbeda. Sebelumnya, hal itu tidak diterima dengan sepenuh hati karena dianggap sistem ini kekurangan unsur manusia yang dibutuhkan dalam pembelajaran.

Namun, dengan kemajuan pesat dalam teknologi dan kemajuan sistem pembelajaran, sekarang ini dianut oleh massa. Pengenalan komputer adalah dasar dari revolusi ini dan dengan berlalunya waktu, saat kita terhubung dengan smartphone, tablet, dll, perangkat ini sekarang memiliki tempat penting di ruang kelas untuk belajar. Buku secara bertahap digantikan oleh materi pendidikan elektronik seperti cakram optik atau pen drive. Pengetahuan juga dapat dibagikan melalui Internet, yang dapat diakses 24/7, di mana saja, kapan saja.

Saat ini e-learning merupakan salah satu alternatif untuk menyelesaikan berbagai masalah dalam pendidikan. Istilah e-learning mengandung pengertian yang sangat luas, beberapa peneliti juga menjabarkan penelitian mereka seputar Pendidikan dan teknologi informasi seperti (Zhang et al., 2006; Moore, Dickson-Deane and Galyen, 2011; Murray and 
Olcese, 2011; Bachtiar, Rachmadi and Pradana, 2014; Khairani, 2014).

\section{Dasar pemikiran e-learning} sesungguhnya adalah prinsip pembelajaran yang bagi siapa saja, kapan saja, dimana saja tanpa dibatasi oleh metode dan media konvensional dalam pembelajaran. Prinsip dasar e-learning menurut filsafat Pendidikan oleh Mason antara lain adalah dengan memberikan kesempatan kepada siapapun yang ingin belajar tanpa dibatasi oleh ruang dan waktu. Kemudian memberikan fleksibilitas dalam interaksi pembelajaran, susunan tematema kurikulum disesuaikan sendiri oleh pembelajar berdasar tingkat kemampuan, kondisi dan kebutuhannya. Prinsip selanjutnya adalah dengan membebaskan peserta didik dalam memilih media sesuai dengan pekerjaan dan tempat masing-masing, mendesain pembelajaran yang sesuai dengan kebutuhan praktis peserta didik di tempat kerja masingmasing, memenuhi kebutuhan masyarakat yang berbeda kebutuhan kurikulum karena memiliki karakteristik masyarakat khusus serta berkontribusi memperbaiki sistem pembelajaran konvensional baik sebagai kurikulum utama, pelengkap atau tambahan serta dalam menciptakan teknik pembelajaran serta meningkatkan profesionalitas guru di berbagai jenjang pendidikan (Mason, 1957).

Namun setiap strategi memiliki kelebihan dan kelemahan. Kelebihan e-learning dalam pembelajaran jarak jauh khususnya antara lain dengan tersedianya fasilitas e-learning supaya antara pendidik dengan peserta didik mudah berkomunikasi tanpa dibatasi oleh jarak, tempat dan waktu. Kemudian pendidik dan peserta didik dapat menggunakan bahan ajar atau petunjuk belajar yang terstruktur dan terjadwal dan antara keduanya bisa saling menilai. Selanjutnya, setiap peserta didik bisa belajar dan merevisi bahan pelajaran setiap saat karena bahan pelajaran yang ada dalam bentuk file dan bisa diubah kapan pun. Setelah itu, apabila butuh tambahan informasi maka peserta didik bisa langsung akses dengan internet. Selanjutnya, update informasi bisa dilakukan dengan browsing internet, dapat pula melakukan diskusi dengan peserta didik yang lebih banyak tanpa dibatasi ruang yang sempit. Peserta didik diharapkan juga menjadi aktif dalam belajar bukan hanya menerima tapi juga bergerak mencari. Kelebihan yang lain dari elearning adalah efisien bagi yang tinggal jauh dari perguruan tinggi atau sekolah konvensional (Welsh et al., 2003).

Sementara kelemahan e-learning adalah sebagai diungkapkan oleh Bullen dan dikutip oleh Rusman sehingga mampu dikelola agar tidak menghalangi proses pembelajaran adalah dari sisi pembentukan values sangat lemah karena interaksi yang terjadi sangat terbatas antara guru dan peserta didik dan peserta didik dengan peserta didik. E-learning juga memiliki kecenderungan mengabaikan akademik dan sosial dan mengedepankan materi dan bisnis sangat tinggi., sehingga pendidikan hanya merupakan pelatihan dan lebih ke arah kognitif. Kelemahan selanjutnya juga adalah perubahan peran peserta didik dari menguasai pembelajaran konvensional menjadi dituntut menguasai teknik pembelajaran yang menggunakan ICT/medium komputer. Kendala bagi yang motivasinya rendah pembelajaran cenderung kurang berhasil, kondisi internet belum merata di semua madrasah dan semua kelas, adakalanya meski di sekolah sudah ada jaringan internet keberadaannya belum merata secara berkualitas. Kemudian, banyak sekolah yang gurunya masih lemah dalam hal pengoperasian komputer termasuk peserta didiknya, serta kurangnya teknisi yang ahli dalam komputer dan jaringan internet termasuk upgrade internet dan instalasi berbagai program (Rusman and Lukman, 2017).

\section{Metode Pembelajaran Bahasa Arab}

Metode pembelajaran merupakan tingkat perencanaan program yang bersifat menyeluruh yang berhubungan erat dengan Langkahlangkah penyampaian materi pelajaran secara prosedural, tidak saling bertentangan dan tidak bertentangan. Metode pembelajaran juga merupakan wadah untuk penerapan materimateri yang terhubung pada pendekatan tertentu. Ada beberapa metode(Effendy, 2005) yang bisa digunakan untuk menyeimbangkan pembelajaran dalam hal ini berkaitan dengan pembelajaran bahasa Arab (Niswah, 2020) dan dapat juga diimplementasikan secara daring yaitu metode komunikatif dan metode langsung. 
Metode komunikatif (الطريقة الاتصالية) Teknik ini adalah merupakan strategi pengajaran yang menciptakan kemampuan dalam mencari tahu bagaimana berbicara dengan bahasa objektif dalam pengaturan informatif asli atau, semua hal dipertimbangkan, sesuai dengan keadaan atau konteksnya. Teknik komunikatif tidak menggarisbawahi dominasi sintaksis atau kemampuan membuat kalimat linguistik, namun pada kapasitas untuk menyampaikan artikulasi yang sesuai dengan situasi unik. Ada beberapa desain Metode Komunikatif, yaitu dari segi tujuan (Umum dan Khusus). Tujuan pembelajaran bahasa dengan metode komunikatif adalah mengembangkan kompetensi pelajar dalam berkomunikasi dengan bahasa target dalam konteks komunikatif yang sesungguhnya atau dalam situasi kehidupan nyata (Thu'aimah, 1989:123). Dengan kata lain metode ini mengkaji bahasa harus sesuai produktivitas ujaran konteks bahasa. Metode komunikatif juga memiliki model Silabus, beberapa tipe silabus yang diusulkan untuk kelas-kelas yang menggunakan metode komunikatif. Silabus struktural plus fungsional dan silabus nasional yang diusulkan oleh (James and Wilkins, 1978), tipe silabus struktural-fungsional-instrumental yang diusulkan oleh Brumfit (Brumfit, 1986). Jupp dan Hollin mengusulkan silabus fungsional dan tipe silabus interaksional oleh Widdowson (Belasco and Widdowson, 1981). Untuk teknik yang paling banyak digunakan adalah penggunaan bahan ajar otentik (min mashadir ashliyyah/authentic material), permainan bahasa (al'ab lughawiyyah/language games), rangkaian gambar cerita (silsilah al-qishshah al-mushawwarah/picture strip story) dan bermain peran (tamtsil daur/role play), penyelesaian masalah (hall almusykilat/problem solving).

Sedangkan dalam Metode langsung dalam metode ini topik sebagai mata kuliah bacaan sebagai ikhtisar kata jargon dan pemanfaatannya dalam kalimat. Aturan bahasa diinstruksikan secara induktif, yaitu mulai dari model dan kemudian mencapai kesimpulan. Baik kemampuan berbicara dan mendengarkan dilatih. Pendidik dan siswa sama-sama dinamis, namun instruktur berperan dalam memberikan peningkatan sebagai contoh wacana, pameran, dan pertanyaan, sedangkan siswa hanya bereaksi dengan meniru, menanggapi pertanyaan, menunjukkan, dll. Desain metode langsung antara lain menggunakan pendekatan yang bertujuan agar para guru yang menggunakan Metode Langsung bertujuan agar para siswa bisa mempelajari bagaimana caranya berkomunikasi dalam bahasa sasaran, dan penting bagi siswa untuk belajar berpikir dalam bahasa sasaran. Metode langsung dalam model silabusnya langsung didasarkan pada berbagai situasi (seperti: satu unit akan berisi dari ungkapanungkapan yang digunakan di bank dan unit yang lain berisi ungkapan-ungkapan ketika berbelanja) atau berbagai topik (seperti: geografi, uang, atau cuaca). Tata bahasa diajarkan secara induktif, yaitu para siswa diperkenalkan dengan contoh-contoh terlebih dahulu lalu mereka berusaha memahami kaidah-kaidah atau generalisasi kaidah yang ada di balik contoh-contoh tersebut.

Masyarakat selalu dibentuk oleh hakikat media yang memungkinkan terjadinya komunikasi efektif, daripada oleh isi komunikasi tersebut." kata Marshall (R.Gani, 1988), sebab itu media atau proses waktu merupakan pola pembentukan kembali ketergantungan antar sosial dan setiap aspek kehidupan personal kita. Hal ini menjadi tuntutan kita dalam menganalisa, mempertimbangkan dan mengevaluasi kembali setiap gagasan ide pokok, perilaku dan kurikulum yang digunakan, media menjadi dasar pembelajaran bahasa Arab untuk menyajikan materi-materi bahasa Arab, alasan ini sesuai dengan pendapat Robert (R.Gani, 1988) yang menegaskan pendekatan respon dan analisis (PRA) seyogyanya mendorong: pengembangan proses berpikir, berbincang dan bertanya para peserta didik. Hal ini sesuai dengan kondisi pendidikan Indonesia, pengajar diharapkan dapat secara cepat beradaptasi dengan keadaan mengolah data, menuangkan ide produktif, kreatif menciptakan, mengolah, mengembangkan, dan mendayagunakan imajinasinya untuk memilih media yang tepat sasaran dan mengembangkan media, metode dan strategi baru.

John Dewey mengemukakan bahwa pendidikan adalah metode dasar dalam 
melakukan reformasi dan kemajuan sosial "I believe that education is the fundamental method of social progress and reform". Pendidikan yang dimaksud meliputi pembelajaran dalam tiga faktor,yakni: pengetahuan, keterampilan, dan pembentukan karakter, seperti yang dinyatakan olehnya: "Learning involves, as just said, at least three factors: knowledge, skill and character. Each of these must be studied" (Dewey, 2009). Seorang guru harus berinovasi dalam menyelenggarakan pembelajaran khususnya pembelajaran bahasa Arab agar peserta didik dapat memahami isi materi dengan baik dan tidak membosankan. Penguasaan materi dan pengembangan materi harus tetap ada dan selalu diperbaharui dengan inovasiinovasi yang ada agar tidak terpaku pada materi saja tetapi dikaitkan juga dengan psikologi anak.

\section{Pembelajaran Berbasis Gim}

Salah satu inovasi pembelajaran yang dapat digunakan di masa pandemi adalah dengan pendekatan digital game-based learning (DGBL), dalam model pembelajaran ini pengajaran dipandang lebih terfokus, sesuai dengan teori konstruktivisme, yaitu teori yang mendukung praktik pembelajaran melalui sentralisasi siswa. Teori ini mendorong siswa untuk secara aktif terlibat dan mengalami pengalaman belajar langsung. Melibatkan siswa dalam proses pembelajaran secara tidak langsung meningkatkan memori dan pemahaman siswa (Furdu, Tomozei and Kose, 2017) dalam jangka panjang. kebutuhan konstan perlu dipupuk sehingga bahasa target dapat dikuasai. Oleh karena itu, gamifikasi bahasa Arab memiliki potensi untuk meningkatkan kemampuan siswa untuk menguasai keterampilan dasar membaca, menulis, berbicara dan mendengarkan. Proses pembelajaran yang melibatkan kegiatan pengulangan dapat memfasilitasi penguasaan bahasa dan praktik selama sesi pembelajaran. Pengulangan dapat membantu proses pembelajaran melalui observasi, pengujian hipotesis dan sintesis yang merupakan tingkat keterampilan berpikir tertinggi (Schaller, 2011).

Singkatnya, pendekatan ini menekankan pada pengembangan motivasi siswa. Motivasi adalah tantangan utama yang perlu diatasi karena dapat mempengaruhi keinginan dan kemampuan seseorang untuk menguasai bahasa. Melalui kegiatan gamifikasi dalam pembelajaran, motivasi peserta didik dapat ditingkatkan baik secara intrinsik dan ekstrinsik (Khaleel et al., 2016) dan dapat membangun kepercayaan diri instan (Soyoof and Jokar, 2014) untuk menyelesaikan tugas yang ditugaskan. Ini dirancang dan disiapkan terbaik sebelum sesi pembelajaran dimulai, sementara itu desain game perlu diseimbangkan sesuai dengan tingkat kesulitan dan tingkat keterampilan para pemain sehingga mereka tidak bosan dengan pertanyaan mudah dan pertanyaan sulit (Putri Fajriati et al., 2020). Pilihan permainan juga harus sejalan dengan konten dan konten penelitian.

\section{METODOLOGI}

Penelitian ini menggunakan pendekatan kuantitatif dengan menggunakan survey. Penulis mengumpulkan dan menganalisis data kuantitatif yang didapatkan dari survey. Data ini diolah, divalidasi dan diinterpretasi dengan menggunakan metode Partial Least Squares Structural Equation Modeling (PLS-SEM). Untuk penelitian menggunakan Pendekatan TAM (Technology Acceptance Model) yang merupakan model yang populer yang digunakan untuk mengukur sejauh mana penerimaan pengguna terhadap teknologi yang diterapkan, dalam hal ini adalah implementasi Digital Game Based Learning untuk pembelajaran bahasa Arab di lingkungan PTKIN. Pemilihan responden dilakukan dengan purposive sampling. Purposive Sampling adalah teknik yang banyak digunakan dalam penelitian kualitatif untuk identifikasi dan pemilihan kasus yang kaya informasi untuk penggunaan sumber daya terbatas yang paling efektif (Patton, 2002).

Model penelitian mengenai adopsi teknologi merupakan sebuah pendekatan alternatif yang efisien untuk studi mengenai penerimaan pengajar terhadap penggunaan teknologi. Salah satu metode yang paling populer di antara model-model pengukuran tersebut adalah TAM (Technology Acceptance Model). Pendekatan TAM (Davis, 1989) diformulasikan berdasarkan prinsip-prinsip TRA (Theory of Reasoned Action) (Hill, Fishbein and Ajzen, 1977) dan TPB (Theory of Planned Behavior)(Ajzen, 1985), dua teori 
yang berasal dari bidang psikologi kognitif, yang menganalisis proses yang mengarahkan seseorang untuk terlibat dalam perilaku tertentu.

TAM dirancang untuk menjelaskan proses penerimaan teknologi dan didasarkan pada dua konsep dasar: persepsi kegunaan (perceived usefulness), dipahami sebagai tingkat di mana seorang individu merasa bahwa penggunaan alat dapat meningkatkan keberhasilannya dalam kinerja bertugas, dan persepsi kemudahan penggunaan (perceived ease of use), yang mengacu pada persepsi individu tentang jumlah upaya yang diperlukan untuk menggunakan teknologi.

Kedua konsep dasar inilah yang mempengaruhi sikap individu terhadap sebuah penggunaan teknologi (A), yang pada gilirannya mempengaruhi niat perilaku penggunaan (BI), yang menentukan penggunaan aktual (AU) sistem informasi

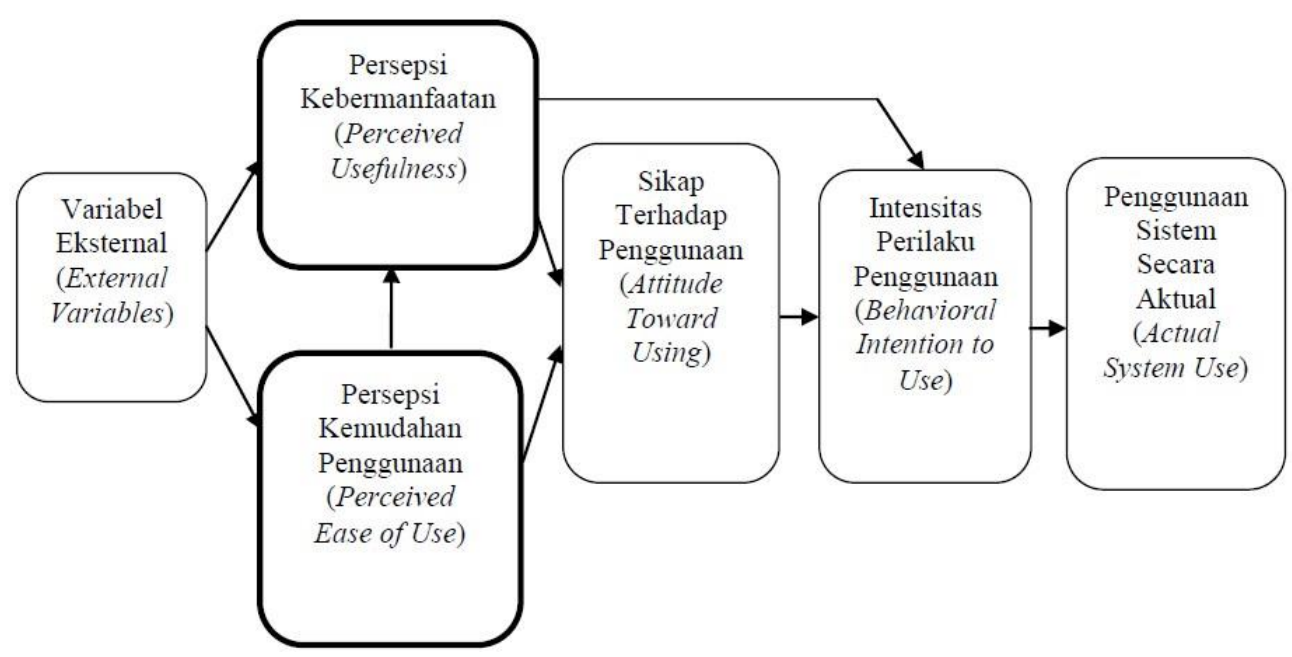

Gambar 1. Diagram Model TAM (Davis 1989)

Keuntungan utama dari teori ini adalah modelnya yang sederhana, mampu beradaptasi dan memiliki kajian teoritis yang semuanya telah menjadikannya model penerimaan yang paling banyak digunakan saat ini (King and $\mathrm{He}$, 2018). Model ini diterapkan di berbagai bidang, dan sering diperluas juga dengan menambahkan konstruksi dari teori lain. Dalam di bidang pendidikan, kita dapat menemukan contoh penggunaannya, baik dengan sikap pembelajar (Abbad, 2011; Bachtiar, Rachmadi and
Pradana, 2014), dan sikap pengajar (Wang and Wang, 2009; Rienties et al., 2016).

Uji hipotesa yang diajukan dalam penelitian ini menggunakan analisis PLS-SEM dengan piranti lunak SmartPLS V.3.3.3 Selanjutnya peneliti membuat kesimpulan dari hasil penelitian yang didapat melalui analisis kuantitatif secara deskriptif guna mendapatkan penjelasan yang telah dikorelasikan dengan teori-teori yang dibutuhkan dan mengacu pada prosedur-prosedur yang telah ditentukan.

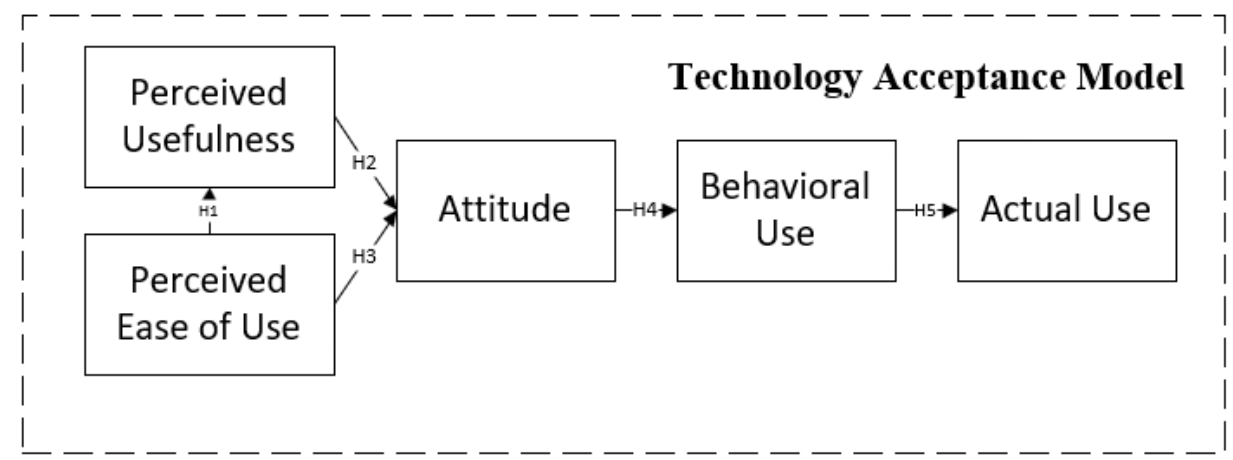

Gambar 2. Model Penelitian yang digunakan

Penelitian ini selain menganalisa penggunaan e-learning dan gim dalam pembelajaran bahasa Arab, juga mengukur tingkat penerimaan penggunaan metode $e$ learning dan gim dengan menggunakan mahasiswa Perguruan Tinggi Keagamaan Islam 
Negeri (PTKIN) sebagai sampel penelitian. Pengumpulan data dilakukan antara bulan Maret hingga April tahun 2021. Sampel dalam penelitian ini adalah mahasiswa PTKIN yang sudah pernah menggunakan media pembelajaran berbasis e-learning ataupun gim untuk belajar Bahasa Arab. Hasil kuesioner pendahuluan yang telah dilakukan kepada 70 responden dan hasil wawancara kepada 5 partisipan yang telah dilakukan. Dari data kuesioner yang sudah didapatkan, beberapa kriteria pembelajaran bahasa Arab yang disukai masyarakat yaitu pembelajaran yang dilakukan secara interaktif yang mengajarkan belajar bahasa Arab dari awal.

Berdasarkan hasil survei, responden didominasi paling banyak dengan jenis kelamin perempuan sebesar $62,9 \%$ dan laki-laki $37,1 \%$. Secara keseluruhan pengguna merasa tertarik belajar bahasa Arab secara online dan rata-rata pengguna merasa kesulitan dalam belajar bahasa Arab. Pengguna sebanyak 74,3\% mengatakan pernah menggunakan internet untuk membantu mempelajari Bahasa Arab. Sebesar $90 \%$ penguasaan kosakata, percakapan, penggunaan tata Bahasa sangat sulit. Dan sebesar $85,7 \%$ menjawab bermanfaat dan akan menggunakannya apabila terdapat aplikasi yang mampu memberikan pembelajaran seperti latihan soal/permainan berpikir. berikut:

Pembangunan hipotesa adalah sebagai

H1: Persepsi kemudahan penggunaan $e$ learning dan gim dalam pembelajaran
Bahasa Arab memiliki dampak positif pada persepsi kebermanfaatan e-learning dan gim dalam pembelajaran Bahasa Arab

$\mathrm{H} 2$ : Persepsi kebermanfaatan e-learning dan gim dalam pembelajaran Bahasa Arab memiliki dampak positif pada sikap terhadap penggunaan e-learning dan gim dalam pembelajaran Bahasa Arab

H3: Persepsi kemudahan penggunaan $e$ learning dan gim dalam pembelajaran Bahasa Arab memiliki dampak positif pada sikap terhadap penggunaan e-learning dan gim dalam pembelajaran Bahasa Arab

H4: sikap terhadap penggunaan e-learning dan gim dalam pembelajaran Bahasa Arab memiliki dampak positif pada intensitas perilaku penggunaan e-learning dan gim dalam pembelajaran Bahasa Arab.

$\mathrm{H} 5$ : intensitas perilaku penggunaan e-learning dan gim dalam pembelajaran Bahasa Arab memiliki dampak positif pada penggunaan sistem secara aktual.

\section{HASIL DAN PEMBAHASAN}

Langkah pertama setelah pengumpulan data dalam penelitian ini adalah dengan menguji instrumen survei terlebih dahulu sebelum mempelajari dan menghitung model konseptual yang diusulkan. Untuk tujuan ini, peneliti melakukan beberapa pengujian, yaitu, memeriksa validitas dan daya tahan model pengukuran yang diusulkan untuk semua struktur model yang digunakan.

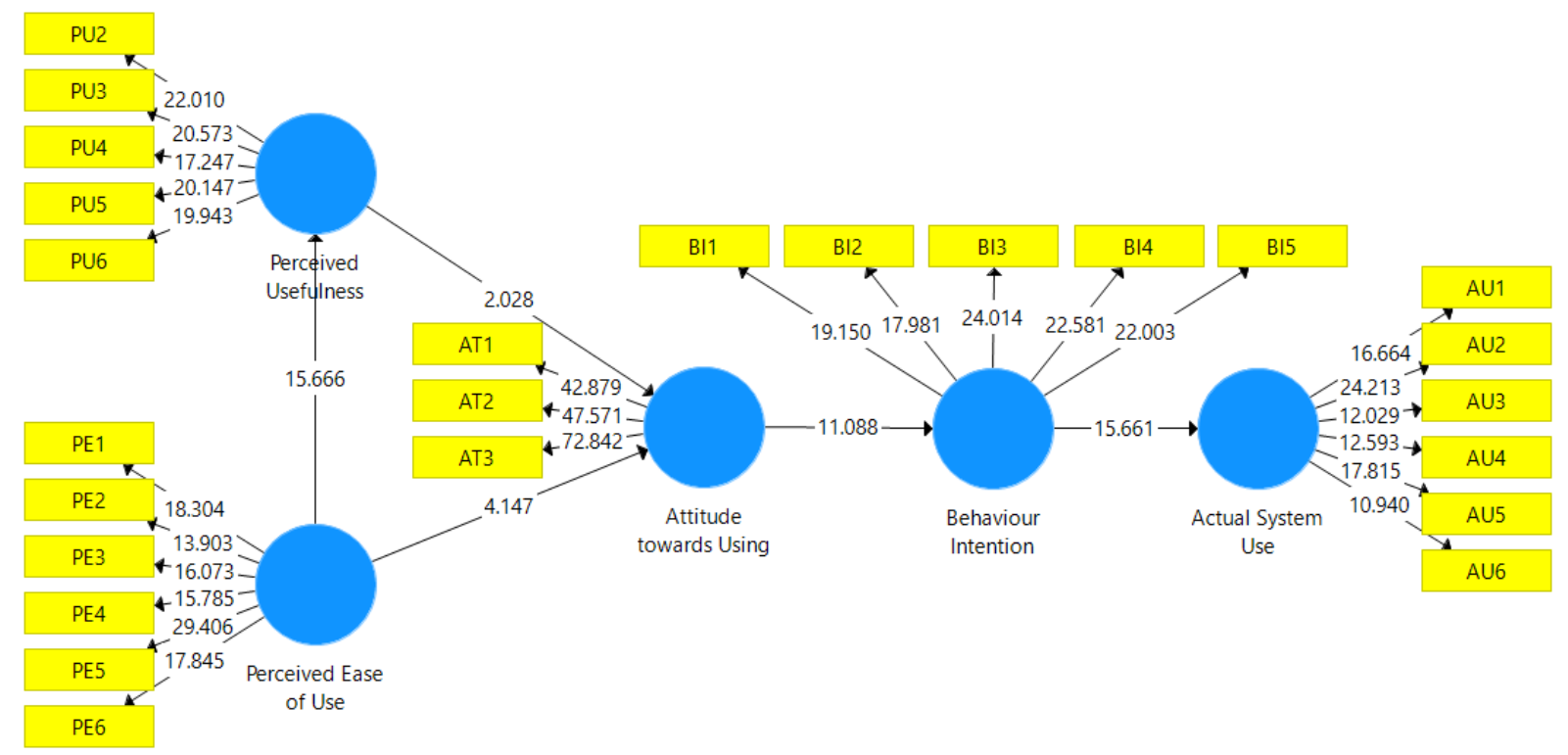

Gambar 3. Hasil Bootsrapping dengan SmartPLS 
Setelah divalidasi, hasil perhitungan dari pengumpulan data kemudian kami melakukan pengukuran model struktural untuk mengevaluasi hubungan antara variabel dependen dan independen. Kami memperoleh evaluasi ini dari proses bootstrap yang dijelaskan pada Gambar 3 yang menghasilkan
T-statistik dan P-Value yang dijelaskan pada Tabel 1. Suatu variabel berpengaruh signifikan jika T-statistic lebih besar dari 1,96 dan P-Value lebih kecil dari 0,05. Hasil tersebut akan mendukung hipotesis jika P-Value kurang dari 0,05 dengan tingkat kepercayaan 95\% (Kock, 2016).

Tabel 1. Hasil Uji Hipotesa

\begin{tabular}{clccc}
\hline Hipotesa & \multicolumn{1}{c}{ Rute } & $\boldsymbol{\beta}$ & P-Value & Kesimpulan \\
\hline H1 & $\begin{array}{l}\text { Persepsi kemudahan penggunaan } \rightarrow \\
\text { Persepsi kebermanfaatan }\end{array}$ & 0.299 & 0.043 & $\begin{array}{c}\text { Hipotesa } \\
\text { diterima }\end{array}$ \\
H2 & $\begin{array}{l}\text { Persepsi kemudahan penggunaan } \rightarrow \text { Sikap } \\
\text { terhadap penggunaan }\end{array}$ & 0.756 & 0.000 & $\begin{array}{c}\text { Hipotesa } \\
\text { diterima }\end{array}$ \\
H3 & $\begin{array}{l}\text { Persepsi kebermanfaatan } \rightarrow \text { Sikap terhadap } \\
\text { penggunaan }\end{array}$ & 0.487 & 0.000 & $\begin{array}{c}\text { Hipotesa } \\
\text { diterima }\end{array}$ \\
H4 & $\begin{array}{l}\text { Sikap terhadap penggunaan } \rightarrow \text { Intensitas } \\
\text { perilaku penggunaan }\end{array}$ & 0.753 & 0.000 & $\begin{array}{l}\text { Hipotesa } \\
\text { diterima }\end{array}$ \\
H5 & $\begin{array}{l}\text { Intensitas perilaku penggunaan } \rightarrow \\
\text { Penggunaan sistem secara aktual }\end{array}$ & 0.714 & 0.000 & $\begin{array}{l}\text { Hipotesa } \\
\text { diterima }\end{array}$ \\
\hline
\end{tabular}

Hasil penelitian ini mendukung penelitian sebelumnya yang mendukung adanya dampak positif antara persepsi kebermanfaatan dan persepsi kemudahan penggunaan teknologi dengan minat penggunaan teknologi.

Media pembelajaran merupakan salah satu perwujudan penggunaan teknologi yang saat ini sangat mempengaruhi hasil belajar siswa dan mendukung kegiatan belajar mengajar, dengan hal ini diharapkan pembelajaran bahasa Arab akan lebih mudah dipahami, menyenangkan dan inovatif. Kemudahan dalam penggunaan teknologi juga memiliki dampak positif dalam mendukung keberlangsungan penggunaan e-learning dan gim dalam pembelajaran bahasa Arab pada masa pandemi COVID-19. Tingkat keberhasilan siswa dalam memahami dan menguasai materi pelajaran bahasa Arab yang diberikan secara daring tergantung dari bagaimana guru berperan dengan baik dalam menyikapi penggunaan, memilih metode, strategi dan konsep pembelajaran bahasa Arab, salah satunya adalah penerimaan sistem pembelajaran dengan bantuan teknologi.

Dengan diimplementasikannya teknologi dan pembelajaran menggunakan bantuan TIK yang diiringi dengan jumlah investasi yang cukup besar yang dilakukan oleh sebuah lembaga pendidikan, belum diketahui apakah mahasiswa akan menghadapi tantangan dalam menggunakan sistem. Pertanyaan lain yang muncul adalah apakah pengguna sistem adalah semuanya mahasiswa atau hanya sebagian mahasiswa saja yang menggunakannya.

Yang harus diketahui selanjutnya adalah apakah dalam penggunaan teknologi pembelajaran dengan TIK dalam pembelajaran akan memotivasi mahasiswa untuk belajar. Selain itu, meskipun banyak Lembaga pendidikan telah menerapkan penggunaan media dan pemanfaatan teknologi dalam proses pembelajaran, hanya sedikit yang melakukan penelitian berdasarkan teori tentang penggunaannya sebagai alat untuk mendukung proses pembelajaran (Pituch and Lee, 2006; Park, 2009). Solusi yang akurat untuk berbagai masalah yang diutarakan seperti itu akan sangat berguna bagi lembaga yang ingin mengadopsi sistem dengan memanfaatan media dan TIK untuk mendapatkan wawasan tentang langkah apa yang harus diambil untuk menggunakan sistem ini di masa depan. Selain itu, identifikasi faktor-faktor yang mempengaruhi penerimaan teknologi sangat penting karena teknologi ini banyak ditawarkan dan diterapkan dalam bidang pendidikan. 
Adopsi dan difusi teknologi yang efektif dalam pendidikan telah menjadi perhatian penting di kalangan praktisi dan peneliti. Penilaian terhadap sebuah sistem juga tergantung pada adopsi dan penerimaannya oleh pihak terkait. Mengingat dampak strategis penggunaan media dan TIK serta peran digital based learning dalam pembelajaran bahasa, ini sudah menjadi cukup berarti untuk menyelidiki faktor-faktor yang mempengaruhi keputusan adopsi untuk teknologi ini untuk diimplementasikan di sebuah lembaga pendidikan, misalnya: Universitas. Lebih lanjut, investasi dalam teknologi informasi inovatif menimbulkan biaya yang sangat tinggi, dengan ketidakpastian yang tinggi mengenai manfaatnya (Dos Santos, 1991); keputusan untuk mengadopsi aplikasi semacam itu lebih awal atau menunggu hingga terbukti berhasil, pada dasarnya penting. Penting juga untuk memahami konteks dimana sajakah ketika sebuah pembelajaran berbasis e-learning ataupun gim dapat diimplementasikan dalam pembelajaran. Pemahaman tentang faktorfaktor yang mempengaruhi ini akan membantu pembuat kebijakan dan praktisi menerapkan sistem ini dan meningkatkan kecepatan pengembangan pembelajaran.

\section{PENUTUP}

Berdasarkan hasil analisis, observasi, studi literatur yang telah disusun, maka dapat disimpulkan bahwa dalam pandemi COVID-19 seperti saat ini dibutuhkan ide dan inovasi baru dalam memilih metode yang tepat dalam menyusun strategi dan konsep pembelajaran, siswa akan dapat merasakan sensasi belajar yang menarik, kreatif, inovatif dan tidak membosankan jika semua konsep pembelajaran berjalan dengan baik. terorganisir dan sistematis. Melalui hasil survey yang dilakukan oleh peneliti, untuk pembuktian kelima hipotesa yang diajukan dan didasarkan oleh teori TAM, maka didapatkan dengan kemudahan penggunaan e-learning dan gim, pengguna setuju bahwa itu dapat meningkatkan persepsi kebermanfaatan dalam pembelajaran Bahasa Arab (H1), kemudahan penggunaan serta kebermanfaatan ini akhirnya juga akan menentukan sikap terhadap penggunaan $e$ learning dan gim ( $\mathrm{H} 2$ dan $\mathrm{H} 3)$. Penelitian ini menunjukkan bahwa korelasi keduanya memiliki korelasi yang kuat yang ditunjukkan dengan $P$-Value $<0.005$. Sikap terhadap penggunaan e-learning dan gim juga berhasil dibuktikan dengan menunjukkan bahwa hal tersebut menentukan intensitas dalam penggunaannya dan berkorelasi kuat terhadap pembelajaran (H4). Pengajar juga diharapkan mampu juga menguasai penggunaan $e$-learning dan gim untuk menunjang pembelajaran karena melalui Hipotesa kelima (H5), hubungan keduanya dapat dibuktikan dengan baik dan berkorelasi kuat, sehingga hal ini menunjukkan bahwa dengan siswa mengakses materi yang lebih intens mampu meningkatkan penggunaan keduanya secara aktual.

Sebagai saran untuk penelitian berikutnya, dikarenakan penelitian saat ini tidak memasukkan penelitian komparatif persepsi penerimaan peserta didik antara sebelum dan sesudah pemanfaatan e-learning dan gim serta dari segi kemudahan keduanya, maka studi selanjutnya harus mempertimbangkan pendekatan ini untuk memberikan gambaran penelitian yang lebih menyeluruh. Dari segi penggunaan teori TAM juga mungkin dapat menggunakan teori yang dimodifikasi khusus dalam konteks pembelajaran Bahasa Arab. Penelitian saat ini juga hanya mengambil sampling peserta didik di lingkungan PTKIN, untuk mendapatkan hasil studi yang lebih komprehensif tentang pemanfaatan e-learning dan gim ini, mungkin studi pada populasi yang lebih luas dibutuhkan, misalnya pada masyarakat muslim di Indonesia secara keseluruhan.

\section{DAFTAR PUSTAKA}

Abbad, M. (2011) 'A conceptual model of factors affecting e-learning adoption', in 2011 IEEE Global Engineering Education Conference, EDUCON 2011. doi: 10.1109/EDUCON.2011.5773286.

Ajzen, I. (1985) 'From Intentions to Actions: A Theory of Planned Behavior', in Action Control. doi: 10.1007/978-3-642-697463_2.

Alessi, S. M. and R.Trollip, S. (2001) 'Multimedia for Learning. Methods and Development', Multimedia for Learning: Methods and Development. 
Alomar, N., Wanick, V. and Wills, G. (2016) 'The design of a hybrid cultural model for Arabic gamified systems', Computers in Human Behavior. doi: 10.1016/j.chb.2016.07.045.

Alshammari, M. T. (2020) 'Evaluation of gamification in e-learning systems for elementary school students', TEM Journal. doi: 10.18421/TEM92-51.

Bachtiar, F. A., Rachmadi, A. and Pradana, F. (2014) 'Acceptance in the deployment of blended learning as a learning resource in information technology and computer science program, Brawijaya university', in 2014 Asia-Pacific Conference on Computer Aided System Engineering, APCASE $2014 . \quad$ doi: 10.1109/APCASE.2014.6924486.

Baid, H. and Lambert, N. (2010) 'Enjoyable learning: The role of humour, games, and fun activities in nursing and midwifery education', Nurse Education Today. doi: 10.1016/j.nedt.2009.11.007.

Belasco, S. and Widdowson, H. G. (1981) 'Explorations in Applied Linguistics', The Modern Language Journal. doi: $10.2307 / 325632$.

Brumfit, C. (1986) The Practice of Communicative Teaching, Pergmaon Institute Of English-Oxford.

Chen, F. H., Looi, C. K. and Chen, W. (2009) 'Integrating technology in the classroom: A visual conceptualization of teachers' knowledge, goals and beliefs', Journal of Computer Assisted Learning. doi: 10.1111/j.1365-2729.2009.00323.x.

Davis, F. D. (1989) 'Perceived usefulness, perceived ease of use, and user acceptance of information technology', MIS Quarterly: Management Information Systems. doi: 10.2307/249008.

Dewey, J. (2009) 'Education as engineering', Journal of Curriculum Studies. doi: 10.1080/00220270802169345.

Dollah, N. H. et al. (2017) Prototype development of mobile app for trilingual Islamic banking and finance glossary of terms via iOS and android based devices,
International Journal of Interactive Mobile Technologies. doi: 10.3991/ijim.v11i3.6620.

Effendy, A. F. (2005) Metodologi Pengajaran Bahasa Arab. Malang: Misykat.

Fairosnita Ibrahim and Kamarul Shukri Mat Teh (2015) 'Pengaruh Permainan Bahasa Terhadap Motivasi Murid Sekolah Rendah Dalam Pembelajaran Perbendaharaan Kata Bahasa Arab', Tinta Artikulasi Membina Ummah. doi: 10.1145/2043662.2043669.

Furdu, I., Tomozei, C. and Kose, U. (2017) 'Pros and Cons Gamification and Gaming in Classroom.: Discovery Service for Univ of South Carolina', BRAIN: Broad Research in Artificial Intelligence \& Neuroscience.

Hamizul, M. and Rahimi, N. M. (2015) 'Design and Development of Arabic Online Games - A Conceptual Paper', Procedia - Social and Behavioral Sciences. doi: 10.1016/j.sbspro.2015.01.771.

Henniger, M. L. (2014) Teaching Young Children: An Introduction 5th Edition. 6th Editio. Woodring College of Education: Pearson. Available at: https://www.pearson.com/us/highereducation/program/Henniger-TeachingYoung-Children-An-Introduction-withEnhanced-Pearson-e-Text-Access-CardPackage-6th-Edition/PGM214033.html (Accessed: 23 August 2020).

Hill, R. J., Fishbein, M. and Ajzen, I. (1977) 'Belief, Attitude, Intention and Behavior: An Introduction to Theory and Research.', Contemporary Sociology. doi: 10.2307/2065853.

Hwang, G. J., Wu, P. H. and Chen, C. C. (2012) 'An online game approach for improving students' learning performance in webbased problem-solving activities', Computers and Education. doi: 10.1016/j.compedu.2012.05.009.

James, C. and Wilkins, D. A. (1978) 'Notional Syllabuses', The Modern Language Journal. doi: 10.2307/324875.

Jasni, S. R., Zailani, S. and Zainal, H. (2018a) 
'Pendekatan Gamifikasi dalam Pembelajaran Bahasa Arab: Gamification Approach in Learning Arabic Language', Journal of Fatwa Management and Research. doi: 10.33102/jfatwa.vol13no1.165.

Jasni, S. R., Zailani, S. and Zainal, H. (2018b) 'Pendekatan Gamifikasi dalam Pembelajaran Bahasa Arab', Journal of Fatwa Management and Research, pp. 358-367.

Kalyuga, M., Mantai, L. and Marrone, M. (2013) 'Efficient Vocabulary Learning Through Online Activities', Procedia Social and Behavioral Sciences. doi: 10.1016/j.sbspro.2013.06.007.

Kaye, A. S. and Holes, C. (1997) 'Modern Arabic: Structures, Functions and Varieties', Language. doi: $10.2307 / 416614$.

Khairani, D. (2014) 'Periodic broadcasting architecture analysis on distance learning system study case', in 2014 International Conference on Cyber and IT Service Management, CITSM 2014. doi: 10.1109/CITSM.2014.7042176.

Khairani, D. et al. (2020) 'Quality in Use Measurement of Google Classroom in Online Learning', in 2020 8th International Conference on Cyber and IT Service Management, CITSM 2020. doi: 10.1109/CITSM50537.2020.9268927.

Khaleel, F. L. et al. (2016) 'Gamification elements for learning applications', International Journal on Advanced Science, Engineering and Information Technology. doi: 10.18517/ijaseit.6.6.1379.

King, W. R. and He, J. (2018) 'A meta-analysis of the Technology Acceptance Model A meta-analysis of the technology acceptance model', Journal of Information Management.

Kirikkaya, E. B., Işeri, Ş. and Vurkaya, G. (2010) 'A board game about space and solar system for primary school students', Turkish Online Journal of Educational Technology.
Kock, N. (2016) 'Hypothesis testing with confidence intervals and $\mathrm{P}$ values in PLSSEM', International Journal of $e$ Collaboration. doi: 10.4018/IJeC.2016070101.

Maskor, Z. M. et al. (2016) 'Teaching and Learning Arabic Vocabulary: From a Teacher's Experiences', Creative Education. Scientific Research Publishing, Inc, 07(03), pp. 482-490. doi: 10.4236/ce.2016.73049.

Mason, R. E. (1957) 'Philosophy of education and educational research', Journal of Educational Research. doi: 10.1080/00220671.1957.10882418.

Mayer, R. E. (2002) 'Multimedia learning', Psychology of Learning and Motivation Advances in Research and Theory. doi: 10.5926/arepj1962.41.0_27.

Moore, J. L., Dickson-Deane, C. and Galyen, K. (2011) 'E-Learning, online learning, and distance learning environments: Are they the same?', Internet and Higher Education. doi: 10.1016/j.iheduc.2010.10.001.

Murray, O. T. and Olcese, N. R. (2011) 'Teaching and Learning with iPads, Ready or Not?', TechTrends. doi: 10.1007/s11528-011-0540-6.

Niswah, U. (2020) 'Taqwīmu al-Kitāb “Ta'līmu al-Lughah al-"Arabiyyah" Lilșaffi alAwwali min al-Madrasah alMutawassițah min Wijḥati Naẓar Rushdī Ahmad Țu'aimah', Lughawiyyat: Jurnal Pendidikan Bahasa dan Sastra Arab. doi: 10.38073/lughawiyyat.v3i1.124.

Orr, G. (2010) 'A review of literature in mobile learning: Affordances and constraints', in 6th IEEE International Conference on Wireless, Mobile and Ubiquitous Technologies in Education, WMUTE 2010: Mobile Social Media for Learning and Education in Formal and Informal Settings. doi: 10.1109/WMUTE.2010.20.

Paiva, A. C. R. et al. (2016) 'iLearnTest Framework for Educational Games', Procedia - Social and Behavioral Sciences. doi: 10.1016/j.sbspro.2016.07.068. 
Papastergiou, M. (2009) 'Digital Game-Based Learning in high school Computer Science education: Impact on educational effectiveness and student motivation', Computers and Education. doi: 10.1016/j.compedu.2008.06.004.

Park, S. Y. (2009) 'An analysis of the technology acceptance model in understanding University students' behavioral intention to use e-Learning', Educational Technology and Society.

Patton, M. Q. (2002) 'Two Decades of Developments in Qualitative Inquiry: A Personal, Experiential Perspective', Qualitative Social Work. doi: 10.1177/1473325002001003636.

Pituch, K. A. and Lee, Y. kuei (2006) 'The influence of system characteristics on elearning use', Computers and Education. doi: 10.1016/j.compedu.2004.10.007.

Putri Fajriati, R. et al. (2020) 'Towards the Implementation of Arabic Language Mobile Apps Learning: Designed by User Insight', in 2020 8th International Conference on Cyber and IT Service Management, CITSM 2020. doi: 10.1109/CITSM50537.2020.9268901.

R.Gani (1988) Pengajaran Sastra IndonesiaRespon dan Analisis. Jakarta: Depdikbud.

Rienties, B. et al. (2016) 'Why some teachers easily learn to use a new virtual learning environment: a technology acceptance perspective', Interactive Learning Environments. $\quad$ doi: 10.1080/10494820.2014.881394.

Rusman, R. and Lukman, L. (2017) 'The Development of an E-learning-based Learning Service for MKDP Curriculum and Learning at Indonesia University of Education', International Research Journal of Engineering, IT and Scientific Research, 3(2), pp. 67-75.

Sakai, M. (2012) 'Preaching to Muslim youth in Indonesia: The dakwah activities of Habiburrahman El Shirazy', RIMA: Review of Indonesian and Malaysian Affairs.

bin Samah, R. et al. (2016) 'Effective Methods in Learning Arabic Language as a Foreign Language', Mediterranean Journal of Social Sciences. Richtmann Publishing. doi: 10.5901/mjss.2016.v7n3p349.

Dos Santos, B. L. (1991) 'Justifying investments in new information technologies', Journal of Management Information Systems. doi: 10.1080/07421222.1991.11517904.

Santoso, H. B. and Fitriansyah, R. (2017) 'Prototype development and usability evaluation of a mobile-based Arabic language learning application', Journal of Engineering and Applied Sciences, 12(8), pp. 1961-1967. doi: 10.3923/jeasci.2017.1961.1967.

Schaller, D. (2011) 'The Meaning Makes It Fun: Game-Based Learning for Museums', Journal of Museum Education. doi: 10.1080/10598650.2011.11510707.

Shelly, G. B., Gunter, G. A. and Gunter, R. E. (2012) Integrating Technology in a Connected World. Cengage Learning.

Soyoof, A. and Jokar, M. (2014) 'Video Game: A Way to Reduce Inhibition and Enhance Language Achievement', Procedia Social and Behavioral Sciences. Elsevier BV, 98, pp. 1850-1858. doi: 10.1016/j.sbspro.2014.03.615.

Sung, H. Y. and Hwang, G. J. (2013) 'A collaborative game-based learning approach to improving students' learning performance in science courses', Computers and Education. doi: 10.1016/j.compedu.2012.11.019.

Umar Tirtaharja (1995) Pengantar Pendidik. Jakarta: Renika Cipta.

Wahab, M. A. (2007) Tantangan dan Prospek Pendidikan Bahasa Arab di Indonesia, Afaq Arabiyah. Available at: http://www.atida.org/melayu/index.php? view $=$ article $\&$ catid $=4 \% 3$ Aarticles $\& i d=5$ 0\%3Atantangan/ (Accessed: 11 February 2020).

Wang, W. T. and Wang, C. C. (2009) 'An empirical study of instructor adoption of web-based learning systems', Computers 
and Education. doi: 10.1016/j.compedu.2009.02.021.

Welsh, E. T. et al. (2003) 'E-learning: emerging uses, empirical results and future directions', International Journal of Training and Development. doi: 10.1046/j.1360-3736.2003.00184.x.

Zeroual, I., El Kah, A. and Lakhouaja, A. (2017) 'Gamification for Arabic Natural Language Processing: Ideas into
Practice', Transactions on Machine Learning and Artificial Intelligence. doi: 10.14738/tmlai.54.3323.

Zhang, D. et al. (2006) 'Instructional video in elearning: Assessing the impact of interactive video on learning effectiveness', Information and Management.

doi: 